\title{
Études françaises et mondialisation : éléments pour un état des lieux
}

\author{
Marie-Manuelle Da Silva \\ CEHUM, Université du Minho, Portugal et DILTEC, Université de la \\ Sorbonne Nouvelle Paris 3
}

\section{Introduction}

Le statut de la langue française, son degré de centralité et l'attraction qu'elle génère dépendent non seulement du degré d'usage de la langue, entendu par Louis Jean Calvet comme le pourcentage de ses locuteurs dans un endroit donné, mais aussi de son degré de reconnaissance et de fonctionnalité qui varie à son tour en fonction du corpus, c'est-à-dire de la quantité de productions réalisées dans la langue, et du statut ${ }^{1}$, à savoir sa place dans la hiérarchie sociale (Moore 27). Les statuts attribués aux langues ont des conséquences sur leur degré de maîtrise, sur l'acquisition de certaines compétences et sur «les attachements ou détachements identitaires des locuteurs » (27), variations qui renvoient à une conception dynamique et complexe de l'identité, reconfigurée en fonction des relations de l'individu au monde. Ces liens de gravitation entre les langues peuvent être étudiés en tant qu'" espaces réels, symboliques et imaginés au sein desquels se dessinent et se négocient des identités locales, nationales et transnationales »(Moore 29). Ainsi, la portée sociopolitique attribuée à la langue française embrasse-t-elle autant les dimensions économiques des espaces géopolitiques désignés comme «francophones» que ses dimensions littéraires et, plus largement, culturelles et identitaires. Je commencerais par revenir à certains éléments de l'histoire qui ont déterminé les scansions du processus de mise en récit que " tout groupe social, tout pays, toute nation produit à son propre endroit » (Warnier 100), puis j'évoquerai la francophonie comme un ensemble d'espaces linguistiques, littéraires et culturels à problématiser dans le cadre de l'extension des études dites françaises et de la mondialisation.

\section{Rappels historiques pour une approche politique}

L'« universalité » du français concerne plus particulièrement les élites européennes et leurs dépendances aux XVII ${ }^{\mathrm{e}}$ et $\mathrm{XVIII}^{\mathrm{e}}$ siècles, puis tous les citoyens de la nation française après la révolution de 1789 associés plus tard au devoir de civilisation des races inférieures par les races supérieures pendant la Troisième République, sous l'orientation d'une politique

\footnotetext{
${ }^{1}$ Cette distinction corpus/statut doit être entendue dans une conception sociolinguistique, c'est-à-dire sociale et non structurale, les «structures » ne pouvant être isolées des pratiques, des représentations et des contextes.
} 
impériale conquérante. Cette notion sera interrogée et reconfigurée dans le cadre de la diversité culturelle face à l'hégémonie de la langue anglaise dans le cadre de la mondialisation et de son imbrication dans l'histoire coloniale et postcoloniale abondamment débattue au cours des dernières décennies.

\section{La langue des élites européennes}

En Europe, c'est à compter du XVII siècle et de la «Querelle des Anciens et des Modernes » que les langues, que l'on nommera nationales avec l'avènement des États-nations, deviennent langues de culture, grâce notamment à la circulation du livre qui concourt à une certaine homogénéisation des usages linguistiques. L'image du français est principalement associée aux fanges sociales privilégiées, contrairement à celle de l'anglais qui " avait été en Angleterre, durant tout le règne de la monarchie normande, l'idiome des masses » (Hagège 20), l'écartant de toute connotation liée à la haute société. La première vague de colonisations, essentiellement menée par des artisans et des soldats originaires du nord-ouest de la France, diffuse quant à elle « un français marqué de certains dialectismes » (Huchon 198) et coupé du français de l'Île-de-France, tandis que les variétés de créole apparaissent au contact du français parlé par les colons dans les sociétés esclavagistes.

Malgré la montée des nationalismes, la mise en cause des modèles classiques français et l'essor de l'Empire britannique, le mythe de l'universalité de la langue atteindra son apogée dans l'Europe des Lumières. L'emblématique concours de l'académie de Berlin en 1784 en est l'illustration bien connue. On en retiendra le sujet, "Qu'est-ce qui a rendu la langue française la langue universelle en Europe ?», qui correspond sans doute à une interrogation réelle sur la fin de la suprématie du français en Europe au profit de l'anglais, et la thèse de celui qui en a remporté le prix. En effet, dans son «Discours sur l'universalité de la langue française », Antoine Rivarol, fidèle au dogme de son époque, développait la thèse d'une primauté intrinsèque du français, celui de Louis XIV, de la cour et des élites, par sa clarté, reflet de l'ordre logique de la pensée, mais aussi par sa rigueur ou encore son élégance qui en ferait, de droit, une langue internationale. Johann Christoph Schwab, qui a partagé le prix de l'Académie de Berlin avec un texte moins connu, a cependant avancé des raisons plus convaincantes. Selon lui, pour que la langue française perde sont statut, « il faudrait ou qu'elle vînt à s'altérer, ou que la culture d'esprit fût négligée dans la nation qui la parle, ou que cette nation perdît de son influence politique, ou que sous ces trois rapports une nation voisine reçût un accroissement proportionnel » (Düwell 43).

L’idéologie du " génie » des langues et du français en particulier en sortait renforcée, ainsi que le sentiment de la richesse exceptionnelle des œuvres écrites dans cette langue. 


\section{La langue de la Nation, des droits de l'homme et des citoyens}

Si le XVII ${ }^{e}$ siècle avait défini les frontières du français en y distinguant le bon du mauvais usage de la langue, la Révolution nourrissait un tout autre projet. Elle imposait le français comme langue « une » de laquelle seraient exclus certains parlers marquant "leur extériorité à l'usage, bon ou mauvais, de la langue nationale » (Merlin-Kajman 172), la langue passant de cette manière du côté du politique. L'ordonnance de Villers-Cotterêts interdisait l'usage du latin et prescrivait celui du français, ou plus exactement du "langage maternel françois ", laissant ainsi place aux idiomes particuliers (De Certeau et al. 11), car il s'agit moins, pour la royauté, de faire parler français que de le faire comprendre, la plus grande partie de la population n'ayant pas accès à la culture écrite.

Le plurilinguisme d'une France rurale où l'on parlait des dialectes et qu'il fallait faire adhérer à un nouvel ordre politique, rendait nécessaires des mesures marquant un tournant à partir de 1793 dont le « Rapport sur la nécessité et le moyen d'anéantir les patois et d'universaliser l'usage de la langue française » de l'abbé Grégoire est représentatif. Préconisant l'uniformisation de la langue de la nation, après une enquête menée auprès d'environ 28 millions d'habitants, ce rapport indiquait que seuls 3 millions maitrisaient la langue (Huchon 206). Ainsi, si l'idiome servait dans les transactions politiques et dans plusieurs villes d'Europe et se propageait à travers la colonisation ${ }^{2}$, il était encore ignoré d'une grande partie des Français...

La République, contrairement à l'Ancien Régime, ne pouvait le tenir à l'écart du Français de l'État, car selon le modèle républicain français, qui a été celui de nombreuses nations européennes émergentes, tous les citoyens devaient, au moins en théorie, avoir accès aux lois, aux textes et aux discours leur permettant de s'exprimer par le vote. Il s'est agi avec la révolution de créer une langue nationale n'ayant pas seulement pour fonction l'expression d'une Révolution « extérieure » à cette langue, mais aussi de dire "un contenu» produit par une politique dans laquelle la langue est subordonnée au projet de la Nation à laquelle elle sert de prémisse (De Certeau et al. 173).

\footnotetext{
${ }^{2}$ Après le conflit colonial franco-anglais de la guerre de Sept Ans entre 1759 et 1762, puis le traité de Paris en 1763, la fin du monopole de la Compagnie des Indes en 1769, le prestige international de la France sera mis en cause et le pays écarté de la scène internationale au profit de la Grande-Bretagne.
} 


\section{La langue de la république et langue universelle de la mission civilisatrice}

L'instauration de l'enseignement primaire laïc, gratuit et obligatoire en 1882 par Jules Ferry sur la base de l'alphabétisation développée sous l'Ancien Régime, et l'interdiction de l'emploi des langues régionales, crée un espace commun «transformant tout sujet en citoyen de la langue » (Sermain 113) à travers l'apprentissage de la langue écrite. Celle-ci est aussi un outil idéologique servant à communiquer l'amour pour la patrie, car contrairement à d'autres contextes nationaux, en France la langue se chargera aussi de la constitution d'une "ethnicité fictive » notamment à travers la représentation d'un passé construit autour de la nation. Jules Ferry étendra d'ailleurs les mesures d'assimilation et de francisation aux colonies, car pour lui comme pour ses contemporains, la colonisation est œuvre de civilisation, de progrès industriel et économique. La langue, outil du développement culturel, véhiculait la conquête partant de la prémisse que les valeurs de la France, coïncidant avec celles de l'humanité tout entière, légitimaient le droit et le devoir de les exporter.

Jules Ferry marquera l'entrée de la $\mathrm{III}^{\mathrm{e}}$ République dans une phase active de la colonisation, renforcée par le vote en faveur de l'expansion coloniale après la conférence de Berlin en 1885 et du "partage de l'Afrique ", continent sur lequel seront d'ailleurs exportées les rivalités linguistiques européennes.

Ainsi, l'universalité de la langue française, comme au demeurant son déclin, est relative tant géographiquement que socialement, car celle-ci remplit les fonctions jugées nécessaires dans des contextes précis. Langue des élites cultivées européennes ou de culture commune pour l'élite internationale; langue du peuple souverain d'après la Révolution; langue porteuse de valeurs et d'idées; ou langue chargée de dire la race, notamment au XIXe siècle « qui placera la question de la nation principalement sous cet angle » (Merlin-Kajman 166) - la dimension politique, idéologique et sociale du processus de construction du lien entre langue et nation a été l'objet d'interrogations nouvelles, en particulier à compter de la seconde moitié du $\mathrm{XX}^{\mathrm{e}}$ siècle qui a vu la disparition de l'empire colonial français et des pertes économiques, politiques, mais aussi culturelles conséquentes.

Le principe de l'acquisition d'une langue et d'une culture, lié à la construction d'une identité commune au moyen de l'exclusion des langues et des cultures autres, ou de la folklorisation de la différence comme corollaire d'une politique de l'unité nationale, est devenu obsolète du fait de l'expansion du français sur le territoire national, de l'indépendance des pays colonisés et des mouvements migratoires du $\mathrm{XX}^{\mathrm{e}}$ siècle. Le fait que la majorité des francophones ne soit plus française et que la langue française ne soit pas nécessairement la seule langue des Français, a provoqué le 
questionnement d'une culture devenue monolingue après la Révolution de 1789 et entraîné son ouverture vers le plurilinguisme et le pluriculturalisme.

\section{Vers un autre universalisme : le français et la diversité culturelle}

Inscrite dans la Constitution de la $\mathrm{V}^{\mathrm{e}}$ République, la langue française est historiquement affaire de l'État, que l'on se réfère à l'État royal, impérial ou républicain. Cette longue histoire, caractérisée par le culte d'une langue unique dans une nation qui s'imagine dès son origine comme monolingue, a fait du français un des éléments constitutifs d'une identité culturelle où fusionnent langue, nation et culture, les politiques culturelles reposant également sur une sédimentation historique.

Si le sentiment de singularité de la culture française, étroitement liée à la manière dont elle est administrée par l'État, remonte au XVII ${ }^{e}$ siècle, l'intervention de l'État dans le domaine culturel s'affirme particulièrement au cours du XXe siècle (Poirrier 10). Sans que l'on puisse encore parler de politique culturelle, c'est avec la monarchie absolue et les règnes de Louis XIII et de Louis XIV que l'intervention de l'État moderne s'affirme dans les domaines des arts et de la culture. La période révolutionnaire voit naître «l'invention du 'patrimoine national' » (Poirrier: 16) développé autour de grands objectifs dont « la conservation du patrimoine hérité, l'éducation du citoyen et la formation libre et indépendante des artistes »(16). La Troisième République créera la loi sur la propriété intellectuelle et le statut d'entrepreneur privé de l'artiste, puis mettra en place une administration au pouvoir renforcé en matière de protection du patrimoine artistique national. Le marché commencera à dicter « les notions de goût, de cote, de prix » (Poirrier: 21) qui supplanteront celles de la tradition, mais ce retrait de l'État ne traduit qu'une évolution des pouvoirs publics, car il reste le principal client des créateurs et le centre de la vie culturelle nationale.

Forte d'un héritage fondé sur une pratique institutionnelle dans le champ culturel, la $\mathrm{V}^{\mathrm{e}}$ République pourra instaurer un ministère des Affaires culturelles confié à André Malraux en 1959 par le Général de Gaulle. Cette nouvelle modalité d'intervention publique marque l'invention de la politique culturelle au moyen d'un chargé de l'expansion et du rayonnement de la culture française avec des moyens bien plus importants que ceux dont disposaient les $\mathrm{III}^{\mathrm{e}}$ et $\mathrm{IV}^{\mathrm{e}}$ Républiques. La politique souhaitée par André Malraux s'adosse à une doctrine et une philosophie au service de l'enseignement de amour de l'art, autrement dit des " génies de l'humanité et notamment ceux de France» (Poirrier 75).

L'idéologie qui primera jusqu'à la moitié des années 1970 mettra en crise la culture "cultivée » et veillera à l'affirmation des identités culturelles des classes dominées, par exemple au moyen des «contre-cultures » provenant de l'underground anglophone. En réponse à cette contestation intellectuelle, 
le concept de développement culturel sera reconnu comme "valeur historique et opératoire pour une société pluraliste »(Poirrier 131) et servira de base aux planifications à venir qui s'assumeront comme sociales et libérales. Aussi la démocratisation de la culture est-elle infléchie par le passage de "l'universalité de la haute culture » (Poirrier 132) réduite aux Arts et Belles-Lettres et sacralisant les œuvres, à une vision plus anthropologique de celle-ci et à une diversification des modalités de sa transmission et de sa diffusion.

\section{L' « exception culturelle » française}

Défendue par la France au sein de l'Union européenne lors des négociations dites de l'Uruguay Round entamées en 1986, l'exception culturelle visait à soustraire la culture aux règles du commerce international appliquées aux services dont font partie «les œuvres de l'esprit », pensées comme porteuses d'une identité culturelle.

Le marché international a atteint un niveau de concentration inédite de groupes multinationaux et multimédias issus de fusions ou de rachats qui met en cause l'autorité des États-nations. L'exception culturelle a émergé d'une négociation internationale à vocation universelle ayant paradoxalement produit des mesures nationales protectionnistes. Par ailleurs, le projet de démocratisation qui légitimait l'action culturelle n'a plus le même sens, car les relations entre le plus grand nombre et les univers culturels sont plus diversifiées aujourd'hui. Ainsi, les profondes mutations des dernières décennies, qu'elles s'opèrent au niveau des mentalités, des pratiques ou des techniques, tant au plan national qu'international, demandent-elles des modèles adaptés. Le service public de la culture se confronte aux logiques économiques du secteur des industries culturelles en pleine transnationalisation. En effet, plus que la culture à proprement parler, il semble que ce soit sa définition et par conséquent celle d'une politique culturelle qui posent problème. L'interrogation de l'opposition entre une " culture marchande » ou " culture de masse » produite industriellement et une culture non marchande censée assurer un lien social ou la recomposition de son tissu, se superpose à l'introduction du thème de la créativité dans ladite "économie de la connaissance » dans les années 1990 et à l'avènement du numérique qui ont entrainé de nouvelles métamorphoses. La configuration des espaces composites et polycentriques de la culture, où s'imbriquent les formes de financement public et privé, la dimension patrimoniale et sa mission de démocratisation, la question de la liberté de création et de la survie des créateurs dans les sociétés multiculturelles, reposent à nouveaux frais la question de la définition de la culture pour laquelle les pouvoirs publics doivent se mobiliser dans le contexte de la mondialisation, de la perte de rayonnement de la France et de la crise financière. Parallèlement, l'avènement du numérique, des modalités d'accès aux œuvres et au savoir et ses 
potentialités de diffusion rendent difficile la mise en place de modèles économiques soutenables. Ce changement de paradigme, à la fois industriel et économique, implique la prise en compte d'un temps et d'un espace de la créativité difficilement compatible avec la politique culturelle française fondée sur le caractère exceptionnel des biens culturels. Aussi, l'émergence de nouvelles pratiques culturelles et artistiques est souvent au centre d'incompréhensions révélatrices du décalage entre les pratiques effectives dans leur diversité et l'idéologie du déclin d'une certaine forme de culture caractérisée par la figure de l'individu cultivé appartenant à l'élite et l'ensemble de ceux qui souhaiteraient une prise en compte de la diversité des pratiques culturelles non reconnues. Ces pratiques étant désormais prises dans le flux des échanges marchands de l'économie contemporaine mondialisée, l'influence des États en matière de culture s'est décentralisée au profit de dynamiques européennes, locales ou émanant des sphères privées auxquelles on emprunte des outils de gestion appliqués au sein de l'action publique. L'avenir des cultures nationales se présente ainsi comme « le défi pour les politiques ayant eu pour référentiel 'un modèle' de culture, de l'adaptation à une pluralité de pratiques, d'expressions artistiques et culturelles qui est la marque du monde contemporain » (Bonnet et Négrier 11).

\section{La diversité culturelle : une autre conception de l'universalité ?}

C'est dans le cadre de ces transformations que le concept d'exception culturelle s'est vu substituer par celui de diversité culturelle, plus consensuel mais aussi plus vague. Ce dernier résout le conflit entre deux slogans à l'origine de lectures divergentes, d'une part, sur le plan local ou interne, la démocratie culturelle, c'est-à-dire « l'égalité entre les genres et les styles » (Wallon 93) et, d'autre part, l'exception culturelle au niveau mondial, ou " la défense du pluralisme et la protection des productions nationales » (93). La notion apparait dans toutes sortes de discours qui se basent aussi bien sur la place de la culture dans les négociations commerciales que sur la pluralité de la définition de culture au sens anthropologique et la défense de minorités.

La question anthropologique de l'identité nationale et le renforcement de catégories comme celles de " minorité » et de " communauté », pointent vers une transformation de la question de l'immigration, des immigrations devrait-on dire, problématisée à partir de l'origine coloniale ou non des populations concernées. L'interrogation sur la pertinence du critère de l'ancienneté des vagues d'immigration plus ou moins récemment installées pour leur " assimilation » ou leur « intégration », autrement dit leur statut social, a conduit à d'autres questionnements sur la place à réserver aux langues minoritaires et aux coutumes des "nouveaux » Français. Si

d'aucuns alertent sur le danger de l'enfermement de l'homme dans l'identité du groupe à laquelle il pourrait se voir réduit, sans possibilité de 
s'en libérer, il semble cependant que ce péril pourrait également être écarté par ce qu'Achille Mbembe, après Jean-Luc Nancy, nomme l'être-encommun (Mbembe 2007) qui consiste dans le partage des singularités.

Cette posture semble indiquer que l'Europe soit en passe de céder son monopole de l'universel, les anciennes métropoles étant "particularisées » et les anciennes colonies " universalisées » (Mathy 361) dans un mouvement d'inversion des rôles qui met moins en cause l'universalisme que sa définition européenne. Ces tensions semblent résulter en partie des dynamiques de la politique mondiale et du passage de l'ordre industriel au postindustriel, telles que les a décrits James Roseneau (Appadurai 200) et qui concentrent plusieurs systèmes, à la fois multicentriques et étatcentriques, dont les conceptions et les frictions enchâssées provoquent des événements et des répercussions en cascade (199). Qui plus est, cela se produit dans le contexte des mouvements de diaspora transnationaux et « a-étatiques » qui n'exigent aucune autonomie nationale. Par ailleurs, la globalisation qui « consiste autant en un processus de mise en relation des mondes qu'en un processus de réinvention des différences » (Mbembe 2007) a favorisé un sentiment cosmopolite qui renvoie à la possibilité d'expérimenter la différence « dans l'acte même par lequel on la subsume et la sublime » (idem) et à son inscription multiple dans plusieurs parties du monde.

\section{La diversification socioculturelle interne de la société française}

La France s'est progressivement accommodée de son entrée dans la diversité culturelle. Cependant, le maintien d'un paradigme universaliste perdure, fidèle à l'idée de " musée imaginaire » d'André Malraux et du rôle de la France dans sa célébration et son partage, mais aussi dans l'action publique de par l'intégration de différentes cultures par l'euphémisation, voire l'élimination, des «contradictions entre les récits » (Négrier 175) qui ne vont pas dans le sens d'un même destin national. Ce «double universalisme historique » (Négrier 176), fondateur de la politique culturelle française est actuellement renversé au profit de l'affirmation d'un «système plus ou moins compatible avec l'universalisme républicain » (Négrier 182) combiné avec des pratiques multiculturalistes locales nées de l'hybridation entre les modèles universaliste et différentialiste.

Plus qu'un déclin de l'identité nationale, nous avons affaire à sa recomposition en comptant parmi les Français les descendants des populations immigrées dont l'identité française se configure en fonction de la nature de l'immigration dans laquelle leur histoire s'inscrit. Par ailleurs, les populations immigrées provenant des anciennes colonies entretiennent des rapports particuliers avec la France. 
En outre, les enjeux géoculturels revêtant, pour ces raisons, une importance stratégique comparable à celle des enjeux géopolitiques et géoéconomiques, il apparaît désormais évident que les entités géoculturelles gagneraient à s'instituer comme aires d'interactions culturelles privilégiées. La vision classique de la «francité » promue au niveau externe et défendue par la centralité étatique représentée par les conseillers culturels et les ambassades dans certains contextes est aujourd'hui confrontée à la pluralité, mais aussi à la nécessité de construire un nouvel espace géopolitique et géoculturel en mesure de rivaliser au niveau international. En effet, l'idée d'une harmonie «naturelle» sous le signe de la langue et de la littérature françaises, que la valorisation des productions culturelles non pas françaises, mais en langue française, rendues manifestes par les décolonisations viennent relativiser, contraignent à reconfigurer les discours en vue de la prise en charge de la profondeur historique qui définit désormais le patrimoine français dénationalisé (Provenzano 2011).

Certains grands ensembles géographiques comme la Méditerranée, caractérisée par le plurilinguisme et le pluriculturalisme ou la Francophonie regroupant des « lieux d'affrontements, qui, sous le prétexte de la langue, recouvrent des sentiments de domination économique et culturelle » (Laulan 46), sont malgré tout considérés comme des laboratoires potentiels du pluralisme culturel mondial au sein desquels la langue française, alliée aux cultures dites francophones, aurait un rôle à jouer. La Francophonie est aujourd'hui fréquemment utilisée comme motif de résistance à la " pensée unique », à l'uniformisation culturelle ou à l'hégémonie de la langue anglo-américaine.

\section{La langue d'un espace géoculturel et géopolitique : la francophonie}

La francophonie moderne, projet destiné à relier les pays « ayant en commun l'usage du français » puis « le français en partage », s'est concrétisée sur le plan institutionnel autour de valeurs communes, d'un « humanisme intégral » unissant tous les continents et toutes les races. Au commencement du projet, il s'agissait pour la France de garantir une expansion linguistique et culturelle et d'affirmer son rayonnement dans un monde bipolarisé par la guerre froide ; et pour les pays africains concernés de s'établir sur le terrain de la modernité. Mais il faudra attendre les années 1980 pour que le volet politique de la francophonie, coordonné par la France, fasse converger les deux principales voies du projet « francophone » franco-centrée d'une politique culturelle nationale et celle, margino-centrée, d'une coopération internationale basée sur un enrichissement culturel mutuel (Provenzano 2011).

Mais l'action de la France dans ses ex-colonies fait de la coopération un outil ambigu, aussi bien sur le plan politique qu'économique et culturel, les 
pays africains concernés représentant des enjeux stratégiques pour des partenariats dans le contexte de la mondialisation de l'économie. La combinaison d'enjeux tels que la conquête de marchés, la promotion d'une langue et d'une culture collective ou l'argument de la diversité culturelle, forme un amalgame rhétorique destiné à convaincre de l'utilité du français au niveau international. Le défi à relever reste sans doute celui de la conciliation entre, d'une part, la défense linguistique et le purisme qui y est associé, la défense de la langue française " classique » et les objectifs monoglossiques de la politique linguistique intérieure et, d'autre part, la coopération internationale guidée par le plurilinguisme et le pluralisme culturel mettant en exergue « les langues françaises » et leur inventivité.

\section{La « francophonie littéraire »}

Le terme fait normalement référence aux littératures non hexagonales en langue française, en partie comparables aux Commonwealth Literatures aussi bien en Europe qu'en dehors de l'Europe et impose en cela une distinction entre la France et les autres cultures où le français est présent. Car il existe une perte symbolique dans le passage de la dénomination "littérature française » à celle de "littératures francophones » dénoncée par les écrivains «francophones » eux-mêmes.

La construction de savoirs sur la francophonie littéraire et son découpage s'est néanmoins élaborée, notamment à partir des principes qui structurent un espace non constitué en tant qu'entité littéraire institutionnelle, de la comparaison de zones littéraires francophones, des modalités de leur rapport à la France ou du dépassement de ces rapports. La littérature dite francophone s'étant frayé un chemin dans la l'histoire littéraire mondiale, bien qu'indexée à la promotion de biens culturels en langue française promus par la France. En effet, la réflexion théorique prise en charge et problématisée notamment par l'institution universitaire, possède une tradition qui suit les scansions du changement de paradigme marquant le discours de la culture. D'une position franco-centrée et monolingue - la « Civilisation de l'Universel » chère à Senghor - à la pluralité culturelle en passant par la construction d'un exotisme tiers-mondiste (Moura 2003) correspondant aux spécificités attribuées à différentes " aires culturelles » (Beniamino 2000) et, par extension, à ses productions symboliques, les enjeux du " dialogue des cultures » s'apparentent aux luttes symboliques menées par exemple par les minorités francophones telles que celles du Québec ou des jeunes États africains dans les années 1970. Parallèlement, des ensembles francophones distincts nationalisés, comme les littératures belge, suisse romande et québécoise, qui possèdent une tradition discursive depuis le $\mathrm{XIX}^{\mathrm{e}}$ siècle, rendent nécessaire un cadre épistémologique qui permette de résoudre la tension entre la prise en compte du fait littéraire francophone dans sa globalité et son articulation au découpage par zones spécifiques, parfois héritières d'une critique constituée en sous-champs 
disciplinaires (les "études québécoises » par exemple). En somme, les « études francophones » se sont élaborées en contrepoint d'une posture normative qui voulait, pour le dire simplement, que l'écrivain francophone maittrise un français « universel » ou classique établi selon le canon littéraire français, mais décrive des réalités locales. Elles appellent également à ce que la problématique francophone s'autonomise des disciplines plus anciennes telles que l'ethnologie, pour les cultures africaines par exemple (Beniamino 60-65), et qu'elles évitent l'écueil de la généralisation autant que celui du morcellement (145). Les approches variationnistes qui en ont découlé à la fin du $\mathrm{XX}^{\mathrm{e}}$ siècle adoptent à l'égard de leur objet une perspective poétique, mais aussi sociohistorique permettant de configurer deux ensembles également déterminés par un rapport de domination à la France littéraire, mais correspondant à des modèles distincts, l'un national (littératures belge, suisse et québécoise) et l'autre postcolonial (littératures maghrébines, africaines et antillaises).

\section{Le français, langue de la postcolonialité}

Si la notion de «postcolonial » désigne d'abord une catégorie historique qui renvoie à l'après colonialisme, notamment quand elle fait référence aux " sociétés postcoloniales » des années 1970 (Lazarus, 2006 : 61), une acception plus tardive, et sans doute plus politique et polémique, se défait de la chronologie linéaire et relie le terme à " une représentation sociale de soi comme 'autre', fondée sur une critique idéologique du discours de la modernité européenne en tant que champ académique spécialisé (à 'déconstruire') au sein des universités principalement occidentales » (Assayag, 2007). L'ampleur de l'ensemble des hypothèses historiques et épistémologiques discutées, des domaines du savoir et des terrains concernés, ainsi que la profusion des approches impliquées dans les études postcoloniales rendent de toute évidence problématique les tentatives de définition d'un champ composé d'entrées à partir de disciplines aussi diverses que la littérature, l'anthropologie, l'histoire, la sociologie ou les sciences politiques. Il semble néanmoins que l'on puisse souligner quelques-uns des traits communs à leur geste fondateur comme " la critique de l'européocentrisme et d'une historiographie élitiste et directive » (Lazarus 17) ; « une commune contestation de la modernité politique et de ses grilles d'interprétation » (Von Busekist 416) ; une manière inédite et mobile de cartographier et de rendre compte des pouvoirs et des régions " des zones de contact entre la métropole et la colonie, ainsi qu'entre les colonies » (Vergès 281) dans laquelle la nation ou l'origine ne sont plus les référents maximaux ; des lectures complexes des héritages ou des remodelages des passés coloniaux dans la société et le monde contemporains, couvrant différentes temporalités et géographies, voulant échapper aux rapports binaires ou unilatéraux et s'interrogeant sur la possibilité d'« une politique du semblable » (Mbembe 120) fondée sur le partage de la différence. 


\section{Études francophones et études postcoloniales}

C'est à partir de la fin des années 1990 que des travaux, comme ceux de Jacqueline Bardolph (2002) ou de Jean-Marc Moura (1999), ont mis en rapport les « études francophones » et les «études postcoloniales » dans la critique littéraire, approches "senties comme antagonistes en France » (Clavaron, 2010 : 40), le postcolonialisme ayant par ailleurs longtemps été considéré comme réservé au seul domaine anglophone. Mais les études francophones peinent à se situer par rapport aux postcolonial studies dont on peut considérer qu'elles constituent une «zone » tout en postulant leur singularité ou leur « exception culturelle » (40).

Par ailleurs, le monde anglophone, moins institutionnalisé, mais plus puissant en tant que réseau économique et politique - davantage que linguistique comme c'est le cas de la francophonie - est ressenti comme une menace, exacerbant les antagonismes et plaçant l'exception culturelle française en position de résistance contre la suprématie d'une hégémonie de la production théorique anglo-saxonne, et la francophonie comme une réponse singulière à la mondialisation. Aussi la défense de la langue française est-elle présentée comme une alternative culturelle, malgré le morcellement et la variété du fait francophone dans le monde. Aux $\mathrm{XX}^{\mathrm{e}}$ et $\mathrm{XXI}^{\mathrm{e}}$ siècles, la francophonie offre la possibilité d'une nouvelle universalité une fois encore centrée sur la langue, ou plutôt sur le discours de la complémentarité des langues et du plurilinguisme. La francophonie est imaginée comme l'espace de la diversité à partir d'une langue, le français, en quelque sorte déterritorialisée et dénationalisée (Mbembe 2006) si l'on considère, comme le suggère Patrick Chamoiseau, que la langue ne sert plus à définir une culture ou une identité (Parker 239).

Cette « réconciliation avec le moi colonisé » (239) permet que le français soit considéré sinon revendiqué, comme c'est le cas pour de nombreux écrivains dits francophones, comme partie intégrante de cultures «non françaises », portée par des identités complexes, transformant la francophonie en phénomène post-colonial, au sens où "les nouvelles générations n'ont rien connu, ni de la colonisation, ni de la décolonisation, ni des joies et des affres des indépendances » (240).

\section{La « post-francophonie »}

L'unification linguistique d'un ensemble littéraire dans le sens d'un décloisonnement de la littérature française pensée comme commune à cet ensemble annule la possibilité pour certaines communautés littéraires hors de France de se constituer en tradition spécifique. Le canon francophone et ses valeurs constitués depuis le centre français conditionnent l'intégration de productions périphériques. Car le « monde littéraire [...] 
s'ordonne selon l'opposition entre les grands espaces littéraires nationaux qui sont aussi les plus anciens, c'est-à-dire les plus dotés, et les espaces littéraires récemment apparus et peu dotés» (Casanova 128) qui forment les deux pôles d'un continuum aux rapports de domination multiples. La concurrence qui définit l'espace de la littérature, aussi bien au niveau national qu'international, parait donc compromettre une coopération littéraire francophone où coexisteraient différents espaces et différents types de concurrence et de domination, le champ littéraire français étant des plus anciens et des plus autonomes et donc des "plus exclusivement voués à la littérature en elle-même et pour elle-même » (131) autrement dit dépolitisé, départicularisé. "Le capital littéraire 'français' a pour particularité d'être aussi patrimoine universel, c'est-à-dire constitutif (et, dans le cas français, fondateur) de la littérature universelle et non pas nationale » (134). La littérature francophone entretient une relation problématique et variable avec un ensemble politique historiquement défini comme "français », mais aussi avec l'ensemble de la littérature mondiale. Car la littérature universelle n'est évidemment pas l'équivalent de la littérature mondiale : la première constitue un canon circonscrit, dans lequel la littérature française est en bonne place, et la seconde, l'ensemble des œuvres du monde présentes et passées, de ce fait impossible à appréhender dans sa totalité, "faute d'une mémoire suffisamment vaste pour l'accueillir » (Pradeau 77), ni même à dénombrer.

\section{Littérature mondiale ou « littérature-monde » ?}

L'encadrement temporel, géographique et politique de la Weltliteratur pensée par Goethe faisait de la littérature européenne le passage obligé pour la légitimation des « littératures lointaines ou naissantes 》 (Pradeau et Samoyault 6). Mais le volume des traductions et des échanges s'accentuant, la notion se libère du point de vue situé qui était le sien et embrasse un " tout dans l'un »(6) qu'il s'agit à présent d'appréhender. Les critères linguistiques, nationaux et historiques s'affaiblissant en tant que facteurs de légitimation et d'autorité des littératures comprises comme une totalité. La confrontation à « ['] impossible saisie du divers » (67) et à la coexistence de textes de diverses provenances et en diverses langues impose un mode d'organisation et l'élaboration d'un appareil méthodologique permettant l'appréhension d'une littérature mondialisée renvoyant à la fois à la mondialisation des échanges et à leur caractérisation.

La notion de littérature mondiale suppose " des mouvements, une circulation, des échanges à voies multiples, des coïncidences de langues » (678) et ainsi des abordages et des lieux théorico-critiques adaptés. Car la littérature est à la fois un ensemble littéraire au statut problématique et un objet d'étude qui engage le choix d'un angle d'approche adapté pour le décrire, que sous-tend sinon une idéologie, du moins un ancrage contextuel qui contribue à lui donner un sens. 
L'uniformisation du littéraire que l'on peut dégager d'une observation synchronique actuelle s'oppose à une perspective diachronique selon laquelle le volume mondial de la littérature, et de son passé, constitué par une pluralité d'histoires propres et spécifiques non superposables à la conception occidentale moderne de la littérature. Il semblerait que la « littérature francophone » pourrait être appréhendée dans ce cadre, aux côtés d'autres littératures soulevant des questionnements similaires (au-delà de la dimension linguistique), comme c'est le cas des littératures « anglophones », « lusophones » ou « hispanophones ».

La « littérature-monde » en français évoquée par Michel Le Bris marque une volonté de transcender la division conventionnelle "français » et " francophone ", pour tendre vers l'idée d'une littérature transnationale mondiale en langue française. L'usage de la catégorie «francophone » dans les universités du Royaume-Uni ou du États-Unis contenait d'ailleurs déjà cette conception élargie, intégrant également les " écritures francophones » qui renvoient aux inéluctables transformations des "coordonnées du paysage culturel » (Thomas 51) en France, que la proposition de Michel Le Bris ne considère pas. La revendication d'une " littérature-monde » exprimée par l'auteur relève davantage d'un positionnement politique contre l'impérialisme culturel français, bien qu'une plus grande prise en compte des auteurs qui écrivent en français semble constituer un gain pour le centre français et non sa transformation en vue d'un meilleur équilibre et partage du champ littéraire soumis aux « logiques du Quartier Latin » (53) ou la construction d'un nouvel espace littéraire «post-francophone ».

Les questions soulevées en 2007 par le Manifeste des 44 écrivains intitulé « Pour une 'littérature-monde' en français » et la diversité des points de vue et des expériences des contributeurs du recueil lui ayant succédé, révèlent la complexité des dissymétries des modes contemporains de contact et d'échange qui sous-tendent la constitution d'un modèle polycentrique de «littérature mondiale» et les limites de la «francophonie» comme catégorie littéraire et mode d'analyse (Xavier 63).

\section{Conclusion}

L'examen des principales étapes de l'histoire de la formation de l'État moderne français et des enjeux linguistico-culturels qui y ont trait, montre que l'expansion de la langue française s'est imposée hors de France à travers la colonisation, mais aussi au niveau interne, en se superposant aux parlers populaires et locaux. Elle s'est vue définie, utilisée ou acceptée par les élites sociales, administratives et politiques, notamment à travers la scolarisation, au bénéfice d'une homogénéité linguistique et culturelle de la population. La définition de la culture nationale dépendante des initiatives du pouvoir a déterminé les éléments les mieux adaptés à la construction 
d'un récit transversal autour d'une identité partagée, des origines et du développement de la nation construite par l'État moderne qui en accroît considérablement la cohérence. Les progrès techniques ont fortement contribué à cette expansion avec la culture de l'imprimé aujourd'hui prolongée par les médias audiovisuels et internet qui ne permettent plus aux États d'exercer le même contrôle sur le récit de la nation, en concurrence avec de potentielles alternatives comme les communautés imaginées tissées autour des différences religieuses, linguistiques, culturelles ou de genre (Bauman 19-21). L'évidence de l'identification d'une société et, partant, d'une culture avec un État-nation a perdu de sa force dans un monde globalisé dans lequel les distances physiques et temporelles sont abolies et les mondes contigus (22), où la réflexion sur la vie et citoyenneté commune est devenue centrale.

Si la nécessité de la construction d'un en-commun, pour autant qu'il soit imaginé et abstrait à la manière dont l'est l'homme de la «Déclaration des droits de l'homme» ou le francophone évoqué par la francophonie, apparaît comme une nécessité, il ne s'agit plus d'assimiler ou d'expulser l'autre désormais "déplacé » dans un espace commun par le flux des mobilités modernes, volontaires ou forcées. Car la dynamique de la globalisation efface la distinction entre un dedans et un dehors et amenuise la souveraineté du pouvoir sur les territoires nationaux.

Si l'Ancien Régime manifestait peu d'intérêt pour la vie des Français, le régime introduit par la Révolution française s'est appliqué à niveler les différences avec les mêmes lois pour tous, mais aussi avec la gestion des modes de production et de distribution des richesses produites au niveau « national ». L'État-nation semble aujourd'hui trop étroit pour des décisions qui ne dépendent plus uniquement de sa souveraineté, mais qui sont prises au niveau transnational (au sein de l'Union européenne) ou au niveau mondial (par des organismes comme l'OMC par exemple), l'État actuel jouant un rôle d'intermédiaire entre producteurs et consommateurs nationaux et le marché mondial, à l'inverse de ce qui se passait au XVIII ${ }^{\mathrm{e}}$ siècle où les forces internationales et supranationales dictaient sa conduite. Les évolutions tant économiques que techniques issues de la révolution industrielle qui ont d'abord servi l'État-nation en dissolvant les particularismes locaux et régionaux, l'affaiblissent à présent puisqu'il ne convient plus comme cadre ni de l'économie, ni de la culture comme l'illustre le cas de « l'exception culturelle française».

Le mythe du français comme langue universelle a progressivement cédé sa place à la réalité d'une langue d'influence mondiale, substitution qui explique en partie le sentiment d'un recul général du français. Le lien que la langue française entretient avec les autres langues a changé : c'est par rapport à une langue de communication dominante, l'anglais, aux langues de ses voisins européens et, plus généralement à la diversité des langues du 
monde, dont certaines sont présentes sur son territoire par les flux migratoires, que celle-ci doit se définir.

En devenant une langue internationale et la langue d'une poétique qui rend compte d'histoires du monde, la langue française semble inéluctablement engagée dans une logique de mondialisation entraînant une remise en cause des dimensions locales et nationales qui orientaient le régime des littératures et des cultures, à la lumière, d'une part, des contextes postcoloniaux et, d'autre part, d'une définition non substantielle de la culture comme circulation des imaginaires, des images et des récits articulant une dimension globale à la tendance homogénéisante du marché littéraire et des appropriations locales déclinées dans une ample variété de langues.

Si l'on admet que la notion de culture renvoie à la circulation du sens en mouvement constant, en rupture avec les vieilles relations et en proie à de nouvelles connexions, il semble inéluctable de s'interroger sur le type d'espace et de signification des codes et des paradigmes culturels qui construiront du sens et de l'identité dans des sociétés inévitablement polyphoniques et plurielles dans lesquelles il est nécessaire de penser les différences, construire une compétence à même de mettre en relation avec l'autre et développer un savoir faire face à la diversité des « habitudes de sens » dans un espace commun. 


\section{Bibliographie}

"Pour une 'littérature-monde' en français." Le Monde, 16 mars 2007.

Assayag, Jackie; Lazarus, Neil (dir.). "The Cambridge Companion to Postcolonial Literary Studies”. L'Homme, no 182, avril-juin 2007. http://lhomme.revues.org/index4132.html. 22/11/2013.

Bauman, Zygmunt. A sociedade sitiada, trad. Barbara Pinto Coelho. Lisboa: Institut Piaget, 2010 [2002].

Beniamino, Michel. La francophonie littéraire. Essai pour une théorie. Paris: L'Harmattan, 2000.

Bonnet, Lluís, Négrier, Emmanuel eds. La fin des cultures nationales? Les politiques culturelles à l'épreuve de la diversité. Paris: La Découverte, 2008.

Casanova, Pascale. La république mondiale des lettres. Paris: Seuil, 2008 [1999].

Clavaron, Yves. «Études francophones, Postcolonial Studies : entre mésentente cordiale et stratégies partagées. » Neohelicon XXXV 2, 2008: 39-53. www.akademiai.com/index/g0t6070n2u511411.pdf. $10 / 11 / 2013$.

De Certeau, Michel, Julia Dominique, Revel, Jacques. Une politique de la langue. La révolution française et les patois. Paris: Gallimard, 2002 [1975].

Düwell, Henning. "L'universalité de la langue française au 18e siècle vue par un allemand : Johann Christoph Schwab». Colloque de la SIHFLES. L"universalité" du français et sa présence dans la Péninsule Ibérique. Université Rovira i Virgili, 28-30 septembre 1995, fle.asso.free.fr/sihfles/Documents/Documents $\% 2018 / D O C \% 201$ $8 \% 20 \mathrm{pdf} / \mathrm{cc} \% 20 \mathrm{~d} 18 \% 20$ duwell.pdf. 13/02/14.

Hagège, Claude. Combat pour le français. Au nom de la diversité des langues et des cultures. Paris: Odile Jacob, 2006.

Huchon, Mireille. Histoire de la langue française. Paris: Le livre de Poche, collection «Références Littérature », 2008 [2002].

Laulan Anne-Marie, Oillo Didier eds. Francophonie et mondialisation. Paris: CNRS Éditions, 2008.

Lazarus, Neil ed. Penser le postcolonial. Une introduction critique, trad. par Marianne Groulez, Christophe Jaquet, Hélène Quiniou. Paris: Editions Amsterdam, 2006.

Le Bris, Michel, Jean Rouaud eds. Pour une littérature-monde. Paris: Gallimard, 2007.

Mathy, Jean-Philippe. “'Refonder l'universalisme' : Bourdieu, Balibar et l'exception' philosophique française." Contemporary French \& Francophone Studies, 12.3, August (2008): 357-364.

Mbembe, Achille. “Qu'est-ce que la pensée postcoloniale ?" Esprit, n³30, décembre (2006): 117-133.

Merlin-Kajman, Hélène. La langue française est-elle fasciste? Langue, pouvoir, enseignement. Paris: Editions du Seuil, 2003.

Moore, Danièle. Plurilinguisme et école. Paris: Didier, 2006.

Moura, Jean-Marc. Exotisme et lettres francophones. Paris: PUF, 2003.

This work is licensed under a Creative Commons Attribution 3.0 License 
Négrier, Emmanuel ed. La fin des cultures nationales? Les politiques culturelles à l'éprewve de la diversité. Paris: La découverte, 2008.

Parker, Gabrielle. "Francophonie et universalité : évolution de deux idées jumelles." Culture post-coloniale 1961-2006. Traces et mémoires coloniales en France. Blanchard, Pascal, Bancel, Nicolas eds. Paris: Autrement, 2005. 228-242.

Poirrier, Philippe. L'État et la Culture de la France au XXe siècle. Paris: Livre de poche, collection «Inédit», Histoire, 2006 [2000].

Pradeau, Christophe, Samoyault, Tiphaine eds. Où est la littérature mondiale? Saint Denis: Presses universitaires de Vincennes, 2005.

Pradeau, Christophe "Un drakkar sur le lac Léman?" Où est la littérature mondiale ? Pradeau Christophe; Samoyault, Tiphaine eds. Saint Denis: Presses Universitaires de Vincennes, 2005. 66-81.

Provenzano François, Vies et mort de la francophonie. Une politique de la langue et de la littérature, Bruxelles: Les Impressions Nouvelles, 2011.

Sermain, Jean-Paul. "Littérature et langue commune : paroles en quête d'écriture. Du classicisme aux Lumières". L'institution des langues. Autour de Renée Balibar. Branca-Rosoff, Sonia ed. Paris : Éditions de la Maison des sciences de l'homme, 2001. 109-124.

Thomas, Dominic. "Decolonizing France: from National Literatures to World Literatures." Contemporary French and Francophone Studies, vol.14, no1, January (2010): 47-55.

Vergès, Françoise. "Postolonialité : retour sur une 'théorie." Retours du colonial? Disculpation et rébabilitation de l'bistoire coloniale. Coquio, Catherine ed. Nantes: L'Atalante, 2008. 277-288.

Von Busekist, Astrid. "Quelle place pour les études postcoloniales dans la science politique française ?" La situation postcoloniale. Les postcolonials studies dans le débat français. Smouts, Marie-Claude ed. Paris: Presses de Sciences Po, 2007. 415-434.

Wallon, Emmanuel. "Esthétique de l'écart et politique de la relation." Raison présente, n¹60, 4ème trimestre 2006: 83-98.

Warnier, Jean-Pierre. La mondialisation de la culture. Paris: La Découverte, 2007 [1999].

Xavier, Subha. "From Weltliteratur to Littérature-monde: Lessons from Goethe for the Francophone World." Contemporary French and Francophone Studies, vol.14, no1, January (2010): 57-65. 